\title{
Surgical resection margin classifications for high-grade pleomorphic soft tissue sarcomas of the extremity or trunk: definitions of adequate resection margins and recommendations for sampling margins from primary resection specimens
}

\author{
Margaret M. Cates ${ }^{1} \cdot$ Justin M. M. Cates $\mathbb{1}^{2}$ \\ Received: 4 February 2019 / Revised: 29 March 2019 / Accepted: 30 March 2019 / Published online: 3 May 2019 \\ (c) United States \& Canadian Academy of Pathology 2019
}

\begin{abstract}
Adequacy of surgical resection margins for soft tissue sarcomas are poorly defined because of the various classifications and definitions used in prior studies of heterogeneous patient cohorts and inconsistent margin sampling protocols. Surgical resection margins of 166 primary, high-grade, pleomorphic sarcomas of the extremity or trunk were classified according to American Joint Committee on Cancer R and Musculoskeletal Tumor Society categories, as well as by metric distance and tissue composition. None of the cases were treated with neoadjuvant therapy. Multivariable competing risk regression models were evaluated and optimal surgical resection margins for each classification system were defined. Minimum safe tumor clearance was $5 \mathrm{~mm}$ without use of adjuvant radiotherapy and $1 \mathrm{~mm}$ with adjuvant radiotherapy. Predictive accuracy of margin classification systems was compared by area under receiver-operating characteristic curves generated from logistic regression of 21/2-year local recurrence-free survival and other standard tests of diagnostic accuracy. The Musculoskeletal Tumor Society and margin distance classifications performed similarly, both of which showed higher sensitivity and negative predictive value compared to the American Joint Committee on Cancer R classification. The prognostic power of close or positive margins in prediction models significantly increased when six or more slides were submitted for assessment of surgical resection margins. Surgical resection margins for soft tissue sarcoma should be reported using the Musculoskeletal Tumor Society classification or metric distance to the closest resection margin. Musculoskeletal Tumor Society wide/radical margins or tumor clearances of $5 \mathrm{~mm}$ (without adjuvant radiotherapy) or $1 \mathrm{~mm}$ (with adjuvant radiotherapy) appear to define the minimum safe surgical resection margins necessary to decrease the likelihood of local recurrence of high-grade pleomorphic sarcomas of the extremity or trunk.
\end{abstract}

\section{Introduction}

The European Society for Medical Oncology recommends that soft tissue sarcomas of the extremity and trunk be excised with negative margins that include a rim of normal

Supplementary information The online version of this article (https:// doi.org/10.1038/s41379-019-0278-9) contains supplementary material, which is available to authorized users.

Justin M. M. Cates

justin.m.cates@vanderbilt.edu

Lancaster Christian Academy, Smyrna, TN 37167, USA

2 Department of Pathology, Microbiology, and Immunology, Vanderbilt University Medical Center, Nashville, TN 37232, USA tissue around the tumor [1]. The National Comprehensive Cancer Network continues to recommend adjuvant radiotherapy for patients with soft tissue sarcoma resected with close soft tissue $(<1 \mathrm{~cm}$ from tumor) or positive resection margins [2]. However, these recommendations are based on a limited number of studies of heterogeneous patient cohorts, particularly in regard to administration of adjuvant radiation therapy. Thus, the minimum margin distance necessary to reduce the risk of local recurrence of highgrade soft tissue sarcoma remains undefined.

A major problem encountered when attempting to synthesize the prior literature is the various classification schemes used to report surgical resection margins for soft tissue sarcoma (Table 1). The Enneking classification (since adopted by the Musculoskeletal Tumor Society) has been a clinically useful surgical definition of resection margin 
Table 1 Classification schemes used to report surgical resection margins for soft tissue sarcoma

\begin{tabular}{|c|c|}
\hline $\begin{array}{l}\text { Margin } \\
\text { classification scheme }\end{array}$ & Definitions \\
\hline \multicolumn{2}{|l|}{ AJCC $R$ system } \\
\hline R0 & Grossly and microscopically negative \\
\hline $\mathrm{R} 1$ & Microscopically positive \\
\hline $\mathrm{R} 2$ & Grossly positive \\
\hline \multicolumn{2}{|l|}{ MSTS system } \\
\hline Radical & $\begin{array}{l}\text { All normal tissue of involved anatomic } \\
\text { compartments excised en bloc }\end{array}$ \\
\hline Wide & $\begin{array}{l}\text { Histologically non-reactive normal tissue } \\
\text { at margin }\end{array}$ \\
\hline Marginal & Pseudocapsule present at margin \\
\hline Intralesional & Tumor present at margin \\
\hline Margin distance & $\begin{array}{l}\text { Metric distance from edge of tumor to } \\
\text { inked surgical resection margin }\end{array}$ \\
\hline
\end{tabular}

AJCC American Joint Committee on Cancer, MSTS Musculoskeletal Tumor Society

status since 1980 [3]. The College of American Pathologists instead mandates provision of a metric distance for reporting negative margins [4]. And the American Joint Committee on Cancer $\mathrm{R}$ system simply reports margins as negative, microscopically positive, or grossly positive [5]. Which method of reporting status of surgical resection margins is most accurate in predicting local recurrence has not been directly analyzed.

There is also a lack of evidence regarding the gross and histopathological assessment of the adequacy of surgical resection margins, with one recent consensus practice guideline noting that "no available evidence-based data addressed how to adequately assess margins" [6]. Therefore, this study was performed to (1) determine the minimum surgical resection margin distance necessary to reduce the risk of local recurrence in high-grade pleomorphic soft tissue sarcomas treated with or without adjuvant radiation therapy, (2) directly compare various margin classification schemes used in the literature, and (3) determine the number of tissue sections needed to adequately evaluate the status of surgical resection margins by histopathologic examination.

\section{Patients and methods}

\section{Patient cohort}

The study protocol was approved by the Institutional Review Board at Vanderbilt University; a waiver of informed consent was obtained. Surgical Pathology files were searched for primary, non-cutaneous, high-grade, pleomorphic soft tissue sarcomas of the extremities or trunk

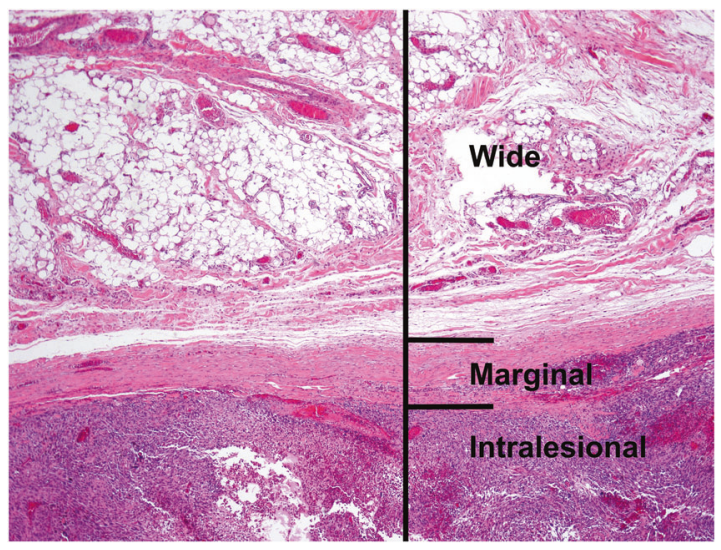

Fig. 1 Photomicrograph of the surgical resection margin of a highgrade pleomorphic sarcoma denoting Musculoskeletal Tumor Society margin classifications (H\&E, 40x)

resected at our institution between 1995 and 2014 without prior neoadjuvant radiotherapy or chemotherapy. Highgrade myxofibrosarcomas were excluded because this sarcoma subtype is associated with higher rates of local recurrence than other sarcomas, most likely because of the tendency of the low-grade myxoid component to grow along fibrous septa in subcutaneous tissues [7, 8]. Tumors with a myxoid component were classified as undifferentiated pleomorphic sarcoma if $<10 \%$ of the total examined area was composed of hypocellular myxoid zones; otherwise, the case was classified as a high-grade myxofibrosarcoma and excluded from the study. Dedifferentiated liposarcomas were similarly excluded given the inherent difficulty in differentially classifying resection margins involved by low-grade and high-grade sarcomatous components and the better overall prognosis of these tumors [9].

Resection specimens were prosected according to standard technique [4]. Briefly, the widths of all surgical resection margins were evaluated grossly and metric distances recorded; in addition to one representative section of tumor per centimeter of its greatest dimension, all surgical resection margins $\leq 2 \mathrm{~cm}$ from tumor were inked and sampled with one or more perpendicular sections. H\&E-stained slides were reviewed to confirm the histologic diagnosis and record the status of surgical resection margins according to American Joint Committee on Cancer and Musculoskeletal Tumor Society criteria [3, 5], as well as the margin distance and the tissue type composing the closest margin (pseudocapsule, fibroadipose, skeletal muscle, or dense regular connective tissue [fascia or periosteum]) (Fig. 1).

Clinicopathologic data, including patient age, sex, tumor size, adjuvant therapy administered, and clinical outcomes (local recurrence-free and disease-free survival) were abstracted from an institutional cancer registry and crossreferenced with electronic medical records. The primary outcome measure was local recurrence. Median follow-up 
for censored patients was 49 months (range, 0.7-181 months). Recurrent disease (or death from sarcoma) occurred in 77 patients $(46 \%)$ a median of 8 months after surgical resection (range, 0.5-62 months). Local recurrence developed in 22 patients $(13 \%)$ a median of 14 months after surgical resection (range, 3-49 months).

\section{Statistical analysis}

Associations and correlations between variables were evaluated using standard bivariate methods. Subhazard ratios for local recurrence-free and disease-free survival were estimated using competing risk regression. Multivariate regression models were developed through stepwise elimination of variables in order of increasing $z$-score. Tumor size and adjuvant radiation therapy were retained as important covariates in all multivariate models because of the known associations between these factors and local recurrence in soft tissue sarcoma [10-18]. Optimal tumor clearance was determined using the Liu method (maximizing product of sensitivity and specificity), Youden method (maximizing their sum), and the "nearest" method (the point on receiver-operating characteristic curve closest to perfect sensitivity and specificity). Predictive accuracy of margin classification systems was directly compared using areas under receiver-operating characteristic curves generated from logistic regression of 21/2-year local recurrencefree survival. All hypothesis tests were two-sided with $\alpha=$ 0.05 . All statistical analyses were performed using Stata v 15 (StataCorp, College Station, TX).

\section{Results}

Clinicopathologic characteristics of the patient cohort $(N=$ 166) are presented in Table 2. There was no missing data. Average patient age was 65 year (SD 16 year; median 68 year [IQR 54-77 year]). Mean tumor size was $10.4 \mathrm{~cm}$ (SD $5.7 \mathrm{~cm}$; median $9 \mathrm{~cm}$ [IQR $5.8-15 \mathrm{~cm}$ ]). Only 19 cases (11\%) had evidence of nodal or distant metastasis at the time of surgical resection. Most patients $(N=108 ; 65 \%)$ received adjuvant radiation therapy after surgical resection. Surgical resection margins were negative (American Joint Committee on Cancer R0) in 138 cases (83\%), with a median minimum margin distance of $1.4 \mathrm{~mm}$ (IQR $0.4-4.0 \mathrm{~mm}$ ). Surgical resection margins were positive in 28 cases.

\section{Pathologic assessment of surgical resection margins}

An average of 13 slides were submitted from resection specimens for histopathologic examination (SD 5.3; median 12; IQR 9-15 cm), of which a mean of 6.5 (SD 2.8; median 6 ; IQR 5-8 cm) were dedicated to assessment of surgical
Table 2 Clinicopathologic characteristics of patient cohort $(N=166)$

\begin{tabular}{|c|c|}
\hline Variable & $N(\%)$ \\
\hline \multicolumn{2}{|l|}{ Sex } \\
\hline Female & $72(43)$ \\
\hline Male & $94(57)$ \\
\hline \multicolumn{2}{|l|}{ Histologic diagnosis } \\
\hline Undifferentiated pleomorphic sarcoma & $126(76)$ \\
\hline Leiomyosarcoma & $24(14)$ \\
\hline Pleomorphic liposarcoma & $14(8)$ \\
\hline Pleomorphic rhabdomyosarcoma & $2(1)$ \\
\hline \multicolumn{2}{|l|}{ Anatomic depth } \\
\hline Deep soft tissue & $136(82)$ \\
\hline Subcutaneous tissue & $30(18)$ \\
\hline \multicolumn{2}{|l|}{ Metastasis } \\
\hline None & $147(89)$ \\
\hline Lymph node & $2(1)$ \\
\hline Lung & $17(10)$ \\
\hline \multicolumn{2}{|l|}{ Adjuvant therapy } \\
\hline None & $56(34)$ \\
\hline Radiotherapy & $100(60)$ \\
\hline Chemotherapy & $2(1)$ \\
\hline Both & $8(5)$ \\
\hline \multicolumn{2}{|l|}{ AJCC lymphovascular invasion } \\
\hline 0 & $147(88)$ \\
\hline 2 & $16(10)$ \\
\hline 3 & $3(2)$ \\
\hline \multicolumn{2}{|l|}{ AJCC $R$ status } \\
\hline R0 & $138(83)$ \\
\hline $\mathrm{R} 1$ & $21(13)$ \\
\hline $\mathrm{R} 2$ & $7(4)$ \\
\hline \multicolumn{2}{|l|}{ MSTS margin status } \\
\hline Wide/radical & $96(58)$ \\
\hline Marginal & $42(25)$ \\
\hline Intralesional & $28(17)$ \\
\hline \multicolumn{2}{|l|}{ Tissue at margin } \\
\hline Pseudocapsule & $42(25)$ \\
\hline Skeletal muscle & $35(21)$ \\
\hline Adipose & $21(13)$ \\
\hline Fibroadipose & $14(8)$ \\
\hline Fascia & $26(16)$ \\
\hline Tumor at margin & $28(17)$ \\
\hline
\end{tabular}

AJCC American Joint Committee on Cancer, MSTS Musculoskeletal Tumor Society

resection margins. As expected, there was a slight decrease in the number of slides submitted for evaluation of margins with increasing tumor clearance (Spearman's $r_{s}=-0.22$; $P=0.009$; Supplementary Fig. 1). Although there was no significant association between submission of additional slides examining tumor margins and documentation of a 


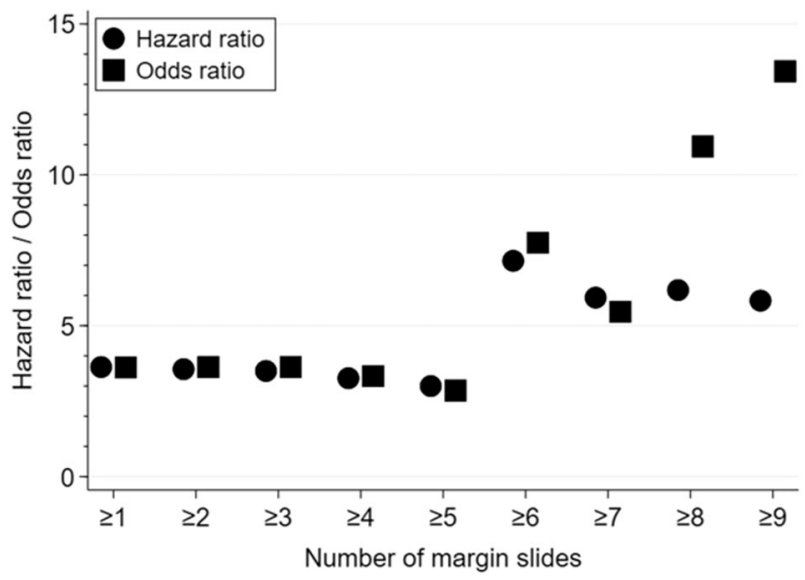

Fig. 2 Hazard ratios from parametric local recurrence-free survival analysis and odds ratios from logistic regression for local recurrence within $2 \frac{1}{2}$ years of surgical resection associated with a positive resection margin (American Joint Committee on Cancer R1/R2; Musculoskeletal Tumor Society intralesional margin) by the number of sections submitted to evaluate surgical resection margins

positive margin (odds ratio per additional slide $=1.08 ; 95 \%$ CI $0.95-1.24 ; P=0.25$; Supplementary Fig. 2), hazard ratios and odds ratios for local recurrence associated with a positive resection margin (tumor present on inked surface) increased significantly when at least six tissue sections were submitted to evaluate the resection margins (Fig. 2). Similar results were obtained when Musculoskeletal Tumor Society margins or optimal margin distance cutoffs were used as the independent variable instead of simply positive vs. negative resection margins (data not shown).

\section{Competing risk regression of local recurrence}

Because patients who die of disease or other causes during clinical follow-up are no longer at risk of local recurrence, a competing risk regression model was used to assess risk factors for this adverse event. None of the variables except for surgical resection margin status and tissue composition of the surgical resection margin were statistically significant in univariable analyses (Supplementary Table 1). Regardless, given prior evidence that increasing tumor size and no administration of adjuvant radiation therapy are associated with an increased probability of local recurrence, subsequent analyses were adjusted for these important risk factors [10-18]. Initial exploratory analyses confirmed that adjuvant radiation therapy is an important confounding factor in assessment of adequacy of surgical resection margins (Supplementary Fig. 3). None of the variables violated the proportional hazards assumption as assessed by variance of coefficients over time (data not shown).

Plots of cumulative incidence functions for local recurrence by each margin classification scheme adjusted for tumor size and adjuvant radiation therapy demonstrate the profound effect of adjuvant radiation therapy in decreasing the risk of local recurrence (Fig. 3 and Supplementary Table 2). For cases not treated with adjuvant radiation therapy, the American Joint Committee on Cancer R system appears to discriminate the level of risk rather well. In addition, adjuvant radiation therapy reduces the risk of an R1 margin to approximately that of an R0 resection. Figure $3 \mathrm{~b}$ shows that marginal and intralesional margins are essentially equivalent and that there is minimal risk of local recurrence with a wide or radical margin in the Musculoskeletal Tumor Society system. Also noteworthy is the marked reduction in the incidence of local recurrence after adjuvant radiation therapy for patients with marginal or intralesional margins, but not wide/radical margins.

For assessment of tumor clearance, margin distance was arbitrarily categorized as positive, $<1 \mathrm{~mm}, 1-2.9 \mathrm{~mm}$, and $\geq 3 \mathrm{~mm}$. In general, increasing tumor clearance corresponds to a decreased incidence of local recurrence (Fig. 3c). But the cumulative incidence of local recurrence for the 17 patients with close $(<1 \mathrm{~mm})$ but negative surgical resection margins not treated with adjuvant radiation therapy is unexpectedly low. Five of these patients did not receive adjuvant radiation therapy because of coexistent metastatic disease, three of whom died of sarcoma within 6 months of surgical resection. Other patients were not treated with radiation therapy post-operatively presumably because of coexistent medical comorbidities, since another five patients in this subgroup died of other causes within 18 months of surgical resection. However, the use of a competing risk regression model should account for these competing events. The low incidence of local recurrence in this group of patients is therefore likely due to the limited follow-up ( $<24$ months) of patients remaining at risk and an unexpectedly low incidence of local recurrence in this small subgroup.

Conversely, four out of 14 patients with resection margins between 1 and $2.9 \mathrm{~mm}$ in width recurred locally within 15 months of surgical resection, resulting in an unexpectedly high cumulative incidence of local recurrence. All four cases were sampled adequately ( $\geq 6$ slides submitted for examination of resection margin status). Notably, margin widths in two of these cases were 1.1 and $1.2 \mathrm{~mm}$, within $200 \mu \mathrm{m}$ of being classified as $<1 \mathrm{~mm}$ in width. Finally, it should be recalled that the sample sizes of the $<1 \mathrm{~mm}$ and 1-2.9 mm margin width subgroups not treated with postoperative radiation therapy are small $(N=17$ and $N=14$, respectively), and that the confidence intervals for these cumulative incidence functions overlap considerably. This might also explain the counter-intuitive results graphically represented in Fig. 3c. Similar findings were observed on conventional Kaplan-Meier local recurrence-free survival curves (data not shown). Nonetheless, there appears to be significant risk of local recurrence in patients not treated 
a

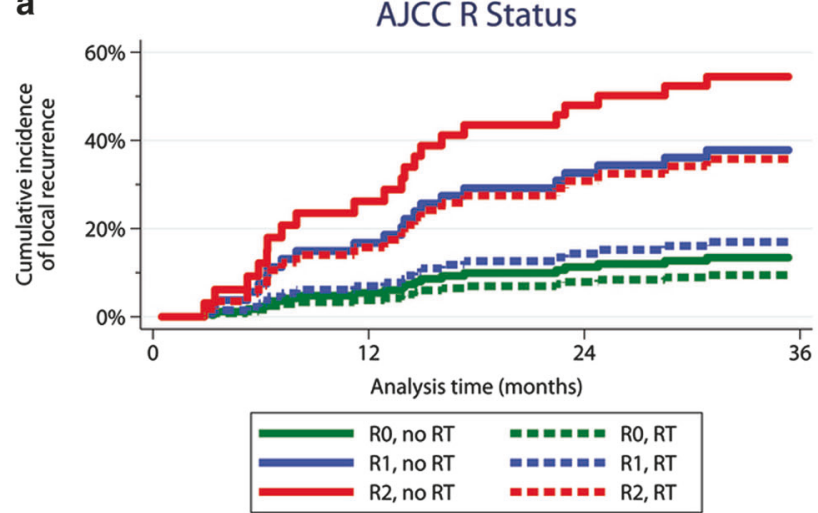

b

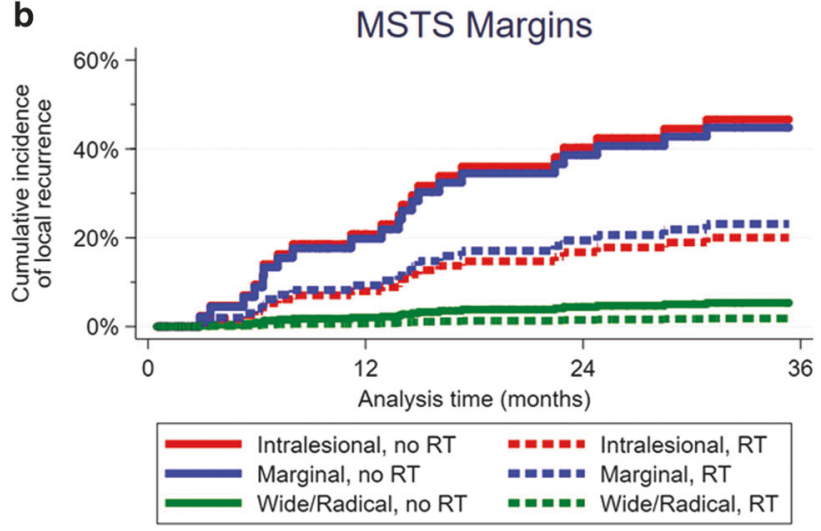

Margin Distance

C

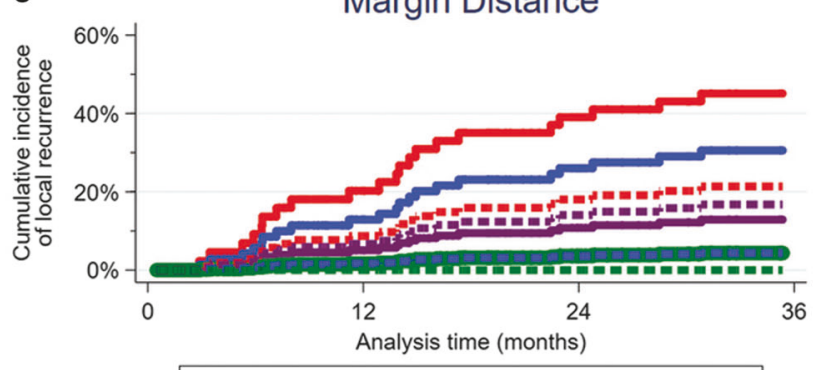

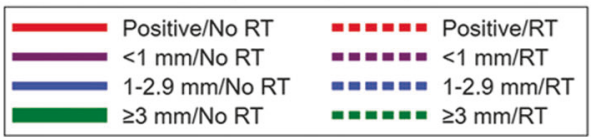

Fig. 3 Cumulative incidence functions for local recurrence by each surgical resection margin classification system adjusted for tumor size and administration of adjuvant radiotherapy. AJCC, American Joint Committee on Cancer; MSTS, Musculoskeletal Tumor Society with post-operative radiation therapy if margin width is $<5$ $\mathrm{mm}$ in metric distance. In contrast, adjuvant radiation therapy markedly reduces the incidence of local recurrence such that surgical resection margins of at least $1 \mathrm{~mm}$ are associated with a minimal risk of local recurrence.

Similar results were obtained when the dependent variable studied in competing risk regression was sarcomaspecific survival (data not shown).

\section{Effect of tissue composition of resection margin}

Assessment of the effect of tissue type comprising the resection margin by multivariable regression was precluded by the limited number of local recurrences in the subgroup with negative margins. For patients not receiving adjuvant radiation therapy, there did not appear to be a significant difference in 21/2-year local recurrence-free survival between patients with closest margins composed of soft tissue (fibroadipose or skeletal muscle) (13 out of 15 cases; $87 \%$ ) or dense regular connective tissue (fascia or periosteum) (3 of 3 cases; $100 \% ; P=0.50)$. Similar findings were observed for patients with soft tissue or dense regular connective tissue at resection margin who did receive adjuvant radiation therapy (2⿺辶/2-year local recurrence-free survival, 21 of
22 cases [95\%] vs. 10 of 10 cases [100\%]; $P=0.49$ ). Conversely, soft tissue or dense regular connective tissue at resection margin was associated with a significantly decreased incidence of local recurrence compared to a margin composed of pseudocapsular tissue (Table 3). A decreased risk of local recurrence was also observed for soft tissue compared to pseudocapsule in competing risk regression analysis (Supplementary Table 1), but this difference failed to reach statistical significance after adjusting for margin distance, tumor size, and adjuvant radiation therapy (Supplementary Table 3).

\section{Local recurrence-free survival rates by surgical resection margin status and adjuvant radiotherapy}

Of the 22 patients who developed local recurrence, 21 $(95 \%)$ did so within $2 \frac{1}{2}$ years of surgical resection. Therefore, 21/2-year local recurrence-free survival was calculated for each margin classification system. Administration of adjuvant radiation therapy is a common practice at our institution, particularly when surgical resection margins are close or positive. Therefore, few cases with positive margins not subsequently treated with adjuvant radiation therapy were available for study. Nevertheless, plots of 
Table 3 21/2-year local recurrence-free survival rates by tissue composition of surgical resection margin in patients who did or did not receive adjuvant radiotherapy

\begin{tabular}{|c|c|c|}
\hline Tissue & $\begin{array}{l}2^{1 / 2-} \\
\text { year LRFS }\end{array}$ & $\begin{array}{l}P \text { (compared to } \\
\text { pseudocapsule) }\end{array}$ \\
\hline Pseudocapsule, no RT & $0 / 5(0 \%)$ & - \\
\hline Soft tissue, no $\mathrm{RT}^{\mathrm{a}}$ & $13 / 15(87 \%)$ & 0.004 \\
\hline $\begin{array}{l}\text { Fascia/ } \\
\text { periosteum, no RT }\end{array}$ & $3 / 3(100 \%)$ & 0.005 \\
\hline Pseudocapsule, RT & $9 / 16(56 \%)$ & - \\
\hline Soft tissue, $\mathrm{RT}^{\mathrm{a}}$ & $21 / 22(95 \%)$ & 0.003 \\
\hline Fascia/periosteum, RT & $9 / 9(100 \%)$ & 0.019 \\
\hline
\end{tabular}

LRFS local recurrence-free survival, $R T$ adjuvant radiotherapy

${ }^{\text {a }}$ Soft tissue (adipose, fibroadipose, and skeletal muscle)

21/2-year local recurrence-free survival rates by surgical resection margin status in patients who did or did not receive adjuvant radiation therapy help to define adequate resection margins in these groups (Fig. 4 and Supplementary Table 2).

For the American Joint Committee on Cancer R system (Fig. 4a), there were too few R1 or R2 cases that did not receive post-operative radiation therapy for analysis. Baseline 21/2-year local recurrence-free survival for cases with R0 margins and no adjuvant radiation therapy was 70\% (16/ 23 cases). For cases treated with radiation therapy after surgical resection, local recurrence-free survival rates for $\mathrm{R} 0$ and R1 cases were equivalent (83\%). The Musculoskeletal Tumor Society margin reporting system showed clear differences between wide/radical resections and marginal or intralesional resections regardless of whether radiation therapy was administered (Fig. 4b). Whereas 89\% (16 of 18) patients with wide or radical margins without adjuvant radiation therapy were free of local recurrence $2 \frac{1}{2}$ years after resection, all seven patients with intralesional or marginal margins not treated with post-operative radiation therapy recurred locally $\left(P<3.2 \times 10^{-5}\right)$. For patients receiving radiation therapy after surgery, 21/2-year local recurrence-free survival rates were $65 \%$ (20/31) for patients with intralesional or marginal margins compared to $97 \%$ (31/32) for patients with wide or radical margins $(P=0.0011)$.

Administration of adjuvant radiation therapy clearly affects determination of an adequate resection margin when defined by margin distance as well (Fig. 4c). For patients not receiving post-operative radiation therapy, a resection margin distance of $<3 \mathrm{~mm}$ resulted in a $2 \frac{1}{2}$-year local recurrence-free survival rate of $43 \%$ (6 of 14 cases) compared to $91 \%$ (10 of 11 cases) for patients with a margin width of at least $3 \mathrm{~mm}(P=0.013)$. Adjuvant radiation therapy increased the $21 / 2$-year local recurrence-free survival rate to $69 \%$ ( 25 of 36 cases) for patients with positive or close $(<1 \mathrm{~mm})$ surgical resection margins. For patients with margins $\geq 1 \mathrm{~mm}$ from tumor, the $2 \frac{1}{2}$-year local recurrencefree survival rate was $96 \%$ (25 of 26 cases) after radiation therapy $(P=0.0086$ compared to close or positive margins). Estimates of cutoff points for defining adequate resection margin width using three different empirical methods were similar: $0.75 \mathrm{~mm}$ if adjuvant radiation therapy is given and $4.5 \mathrm{~mm}$ if not. For subsequent analysis, adequate margin width was therefore defined as $\geq 1 \mathrm{~mm}$ if adjuvant radiation therapy is given and $\geq 5 \mathrm{~mm}$ if not.

One case recurred locally 14.5 months after surgical resection with a 4-mm (Musculoskeletal Tumor Society wide) margin. Although the tumor was $18 \mathrm{~cm}$ in greatest dimension, only three slides were submitted for analysis of surgical resection margins, probably because the closest margin noted on gross examination was $4 \mathrm{~mm}$ of skeletal muscle. Adjuvant radiation therapy was not given to this patient. Two other cases with Musculoskeletal Tumor Society wide resection margins and $\geq 5$ slides submitted to evaluate resection margins recurred locally. One case with a 0.7-mm margin composed of normal adipose tissue recurred 3 months after resection despite receiving adjuvant radiation therapy. The other case recurred 6 months after resection with a 2.5-mm margin of skeletal muscle and no adjuvant radiation therapy. No lymphovascular invasion was noted in the cases that recurred locally despite widely negative surgical resection margins.

\section{Predictive accuracy of surgical resection margin reporting systems for 21/2-year local recurrence-free survival}

Logistic regression was performed with and without adjustment for tumor size and administration of adjuvant radiation therapy to assess the accuracy with which the different margin classification systems predicted local recurrence within $2 \frac{1}{2}$ years of surgical resection (Fig. 5 and Supplementary Table 4). Comparison of the resultant areas under receiver-operator characteristic curves suggest that, in isolation, Musculoskeletal Tumor Society margins $(81 \%)$ and margin distance $(70 \%)$ are more accurate than American Joint Committee on Cancer R status (57\%; $P=0.0028$ and $P=0.0083$, respectively). However, once adjuvant radiation therapy and tumor size are accounted for, these differences in predictive accuracy were no longer statistically significant $(P=0.14)$.

\section{Diagnostic accuracy of surgical resection margin classifications}

Each margin reporting system was then dichotomized at optimal cutoff points and assessed as a diagnostic test for prediction of local recurrence. American Joint Committee 

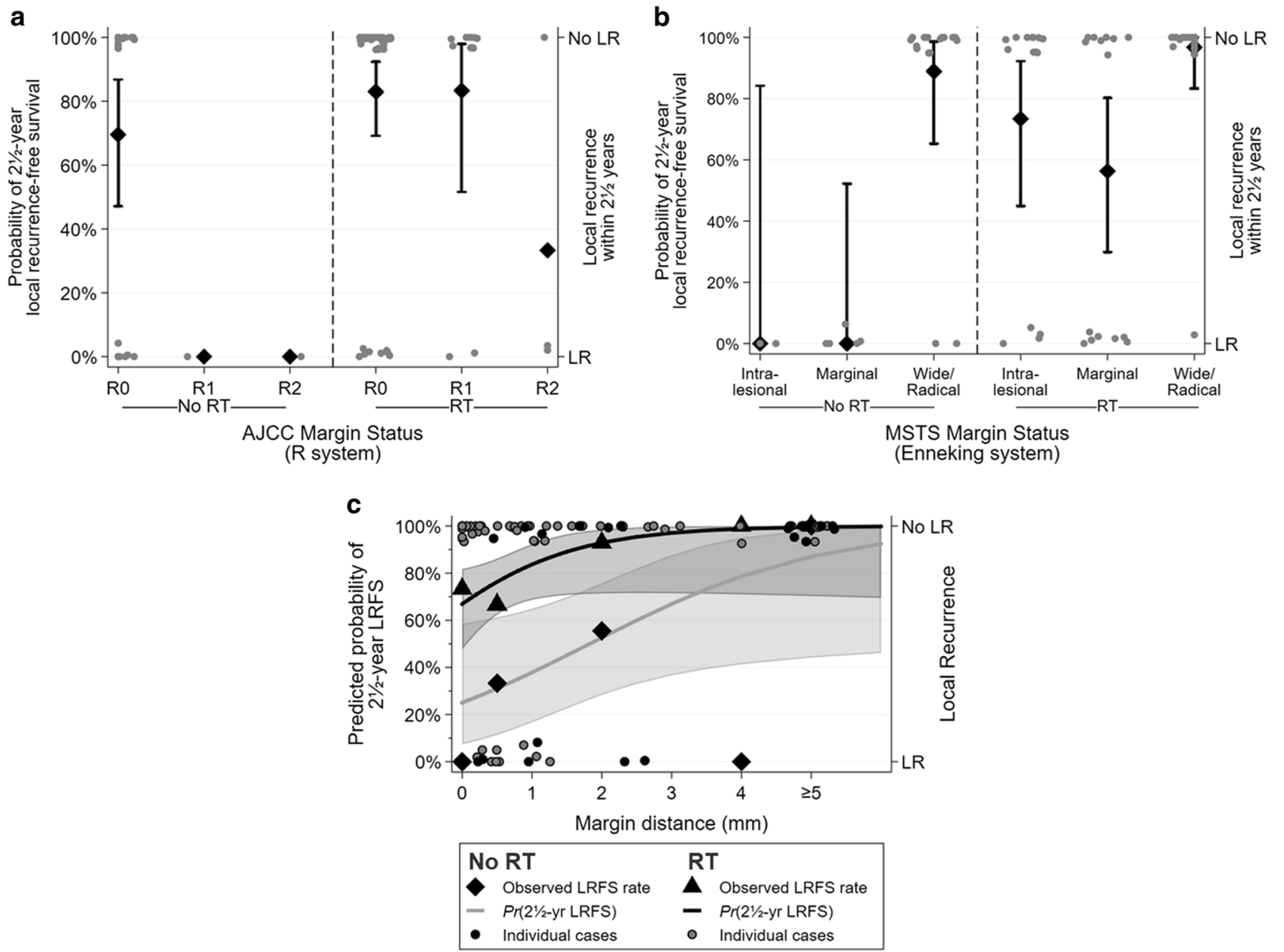

Fig. 4 Crude $2 \frac{1}{2}$-year local recurrence-free survival rates (with $95 \%$ confidence intervals) by (A) American Joint Committee on Cancer (AJCC) R system, (B) Musculoskeletal Tumor Society (MSTS) margin classification, and (C) margin distance in patients who did or did

not receive adjuvant radiotherapy. Predicted probabilities and 95\% confidence intervals from logistic regression analysis are also plotted for margin distance
Fig. 5 Receiver-operator characteristic curves for each surgical resection margin classification system generated from (A) univariable logistic regression and (B) multivariable logistic regression adjusting for tumor size and administration of adjuvant radiotherapy. AJCC, American Joint Committee on Cancer; MSTS, Musculoskeletal Tumor Society a

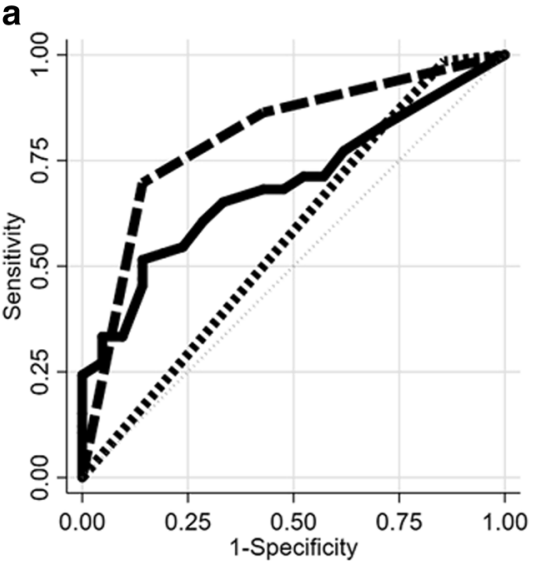

'"',',', AJCC R status $(57 \pm 6 \%)$

- MSTS margins $(81 \pm 5 \%)$

Margin distance $(70 \pm 6 \%)$ b

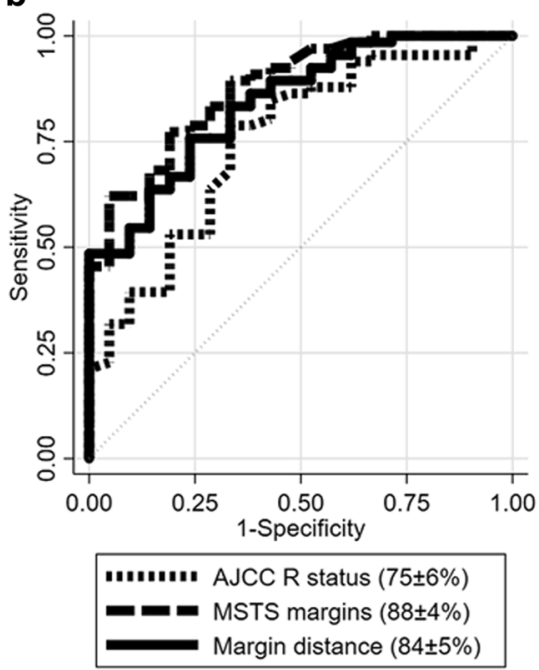


Fig. 6 Diagnostic performance of optimally dichotomized surgical resection margin classification systems (A) Sens., sensitivity; Spec., specificity; PPV, positive predictive value; NPV, negative predictive value); (B) LR+, positive likelihood ratio; Inv.LR-, inverse (reciprocal) of negative likelihood ratio; DOR, diagnostic odds ratio [LR +/LR-]). AJCC, American Joint Committee on Cancer; MSTS, Musculoskeletal Tumor Society
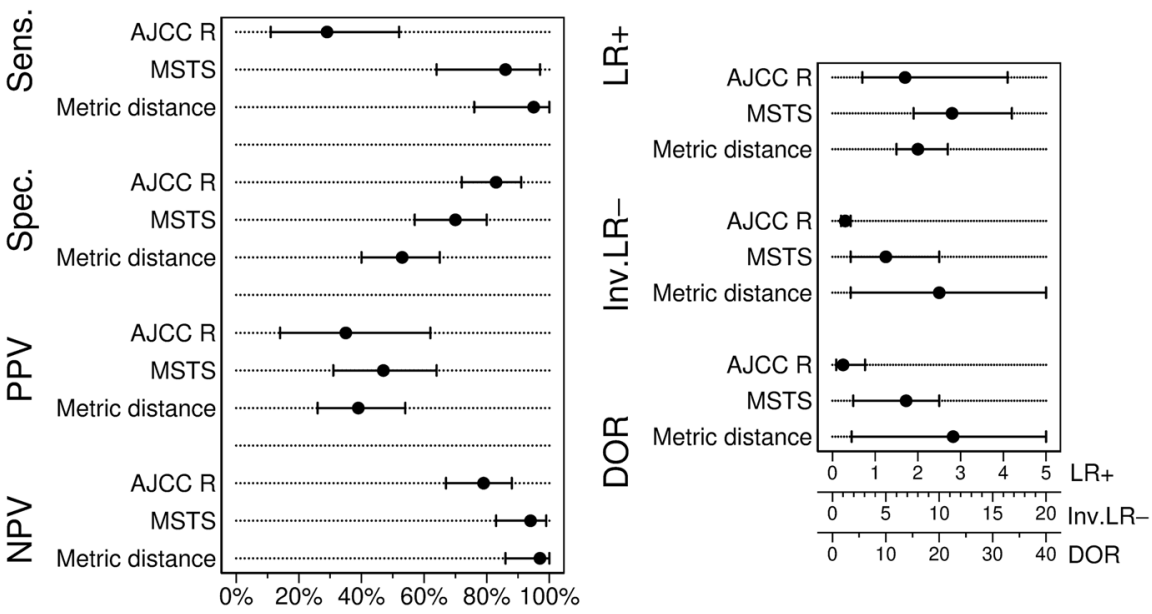

on Cancer $\mathrm{R}$ status was classified as negative (R0) or positive (R1 or R2). Musculoskeletal Tumor Society margins were classified as adequate (wide/radical) or inadequate (intralesional or marginal). Adequate margin distance was defined as $\geq 1 \mathrm{~mm}$ with adjuvant radiation therapy and $\geq 5 \mathrm{~mm}$ without adjuvant radiation therapy. While tests of diagnostic accuracy were generally similar for the Musculoskeletal Tumor Society and margin distance classifications, both showed evidence of superiority over the American Joint Committee on Cancer R system in terms of sensitivity, negative likelihood ratio, and negative predictive value as demonstrated by non-overlapping $95 \%$ confidence intervals (Fig. 6 and Supplementary Table 5).

Of the 21 cases classified with American Joint Committee on Cancer R0 margins but considered inadequate in the Musculoskeletal Tumor Society system (marginal margins), $12(57 \%)$ recurred within 21/2 years. Similarly, local recurrence developed in 14 of 34 (41\%) R0 cases resected with inadequate margin width. Fifteen cases were resected with inadequate margin width but were considered wide or radical in the Musculoskeletal Tumor Society classification; three $(20 \%)$ of these cases recurred locally. Only two cases with marginal resection margins were resected with margins considered adequate by metric distance criteria.

\section{Discussion}

Many prior studies have attempted to define the minimum margin of surgical resection required to reduce the risk of local recurrence for soft tissue sarcoma (Table 4) [8, 11, 13, 14, 19-33]. Unfortunately, the patient cohorts in most of these studies were too heterogeneous (with inclusion of recurrent tumors, re-excisions of previously incompletely excised tumors, tumors with markedly different biological potential [i.e., well-differentiated liposarcoma or other low-grade sarcomas], and variable usage of [neo]adjuvant therapy) for definitive conclusions to be made regarding the optimal width of surgical resection margins. Moreover, the various margin classifications and definitions used apparently befuddled some consensus experts, since the European Society for Medical Oncology guidelines for reporting surgical resection margins are selfcontradictory; assessment of Musculoskeletal Tumor Society margin status is not possible given only the "status of inked margins and the distance between tumor edge and the closest inked margins" [1]. Therefore, this study was performed to determine the minimum margin width necessary to reduce the risk of local recurrence in a relatively homogenous cohort of high-grade pleomorphic soft tissue sarcomas of the extremity or trunk not treated with neoadjuvant therapy while controlling for the confounding effects of adjuvant radiation therapy and tumor size.

The optimal Musculoskeletal Tumor Society resection margin in this study was determined to be wide or radical regardless of whether tumors were treated with adjuvant radiation therapy. This result in agreement with Enneking's original assessment and other subsequent studies of the Musculoskeletal Tumor Society system in classifying resection margins for soft tissue sarcoma [13, 28]. With the increased use of adjuvant radiation therapy, it was later suggested that the local recurrence rates associated with both wide/radical or marginal/intralesional resection margins could be significantly reduced [19, 22, 29, 31]. More recent studies have seemingly abandoned the Enneking concept of resection margins in favor of reporting margin distance. Unfortunately, the Vanderbilt cohort of high-grade pleomorphic sarcomas not treated with neoadjuvant therapy is too small to analyze margin distance as a continuous variable [34]. Therefore, margin distance was categorized arbitrarily for statistical analysis. In this manner, a resection margin width of at least $5 \mathrm{~mm}$ was determined to be adequate if no adjuvant radiation therapy is administered, but this could be reduced to $1 \mathrm{~mm}$ if post-operative radiotherapy 
Table 4 Prior studies examining surgical resection margins in soft tissue sarcomas primarily of the extremities or trunk

\begin{tabular}{|c|c|c|c|c|c|c|c|}
\hline Author & Classification & $N$ & LR & Metric & $\begin{array}{l}\text { LR rate } \\
(\%)\end{array}$ & $\begin{array}{l}\text { Adjuvant } \\
\text { therapy }\end{array}$ & $\begin{array}{l}\text { Cohort } \\
\text { heterogeneity }\end{array}$ \\
\hline \multirow[t]{5}{*}{ Enneking, [28] } & & & & Crude LR & & None & Recurrent tumors \\
\hline & Radical & 24 & 1 & & 4.2 & & Prior excision \\
\hline & Wide & 12 & $3^{\mathrm{a}}$ & & 30.0 & & Subtypes \\
\hline & Marginal & 4 & 2 & & 50.0 & & Grade \\
\hline & Intralesional & 0 & 0 & & - & & \\
\hline \multirow[t]{4}{*}{ Alho [29] } & & & & Crude LR & & & Subtype ${ }^{b}$ \\
\hline & Wide & 145 & 8 & & 5.5 & & \\
\hline & Marginal+RT & 21 & 2 & & 9.5 & & \\
\hline & Marginal & 19 & 7 & & 36.8 & & \\
\hline \multirow[t]{3}{*}{ Bell [30] } & & & & Crude LR & & RT & Subtype \\
\hline & + or $<1 \mathrm{~mm}$ & 48 & 24 & & 50.0 & & Grade \\
\hline & $\geq 1 \mathrm{~mm}$ & 52 & 4 & & 7.7 & & \\
\hline \multirow[t]{5}{*}{ Stotter [31] } & & & & 3-yr LR & & $\pm \mathrm{RT}$ & Subtype $^{\mathrm{b}}$ \\
\hline & $\begin{array}{l}\text { Wide/radical } \\
+\mathrm{RT}\end{array}$ & 24 & 3 & & 11.0 & & Grade \\
\hline & Wide/radical & 17 & 5 & & 29.0 & & \\
\hline & $\begin{array}{l}\text { IL/marginal } \\
+\mathrm{RT}\end{array}$ & 73 & 25 & & 34.0 & & \\
\hline & IL/marginal & 61 & 34 & & 56.0 & & \\
\hline \multirow[t]{4}{*}{ Herbert [32] } & & & & 5-yr LR & & $\pm \mathrm{RT}(92 \%)$ & Subtype ${ }^{b}$ \\
\hline & $>5 \mathrm{~mm}$ & 37 & 0 & & 0.0 & & Grade \\
\hline & $\leq 5 \mathrm{~mm}$ & 10 & 1 & & 20.0 & & $\begin{array}{l}\text { Neoadjuvant } \\
\text { RT }(8 \%)\end{array}$ \\
\hline & Positive & 19 & 6 & & 55.0 & & \\
\hline \multirow[t]{5}{*}{ Pisters [33] } & & & & 5-yr LR & & \pm Brachytherapy & Recurrent tumors \\
\hline & $>1 \mathrm{~mm}+\mathrm{BRT}$ & 63 & 8 & & 12.7 & & Subtype \\
\hline & $>1 \mathrm{~mm}$ & 72 & 20 & & 27.8 & & Grade \\
\hline & $<1 \mathrm{~mm}+\mathrm{BRT}$ & 15 & 5 & & 33.3 & & \\
\hline & $<1 \mathrm{~mm}$ & 14 & 5 & & 35.7 & & \\
\hline \multirow[t]{5}{*}{ Trovik [19] } & & & & 5-yr LR & & $\pm \mathrm{RT}$ & \\
\hline & IL/marginal & 64 & 25 & & 39.0 & & \\
\hline & $\begin{array}{l}\text { IL/marginal } \\
+\mathrm{RT}\end{array}$ & 119 & 28 & & 24.0 & & \\
\hline & Wide & 198 & 50 & & 25.0 & & \\
\hline & Radical & 10 & 0 & & 0.0 & & \\
\hline \multirow[t]{5}{*}{ McKee [11] } & & & & 5-yr LR & & $\pm \mathrm{RT}$ & Subtype $^{\mathrm{b}}$ \\
\hline & $\geq 10 \mathrm{~mm}$ & 53 & 8 & & 16.0 & & Grade \\
\hline & $3-9 \mathrm{~mm}$ & 32 & 10 & & 31.0 & & \\
\hline & $1-2 \mathrm{~mm}$ & 13 & 5 & & 39.0 & & \\
\hline & Positive & 13 & 6 & & 46.0 & & \\
\hline \multirow[t]{3}{*}{ Gronchi [20] } & & & & 10-yr LR & & $\pm \mathrm{RT}$ & Subtype $^{\mathrm{b}}$ \\
\hline & $>1 \mathrm{~mm}$ & 556 & 72 & & 13.0 & & Grade \\
\hline & $\leq 1 \mathrm{~mm}$ & 86 & 25 & & 29.0 & & \\
\hline \multirow[t]{4}{*}{ Dickinson [21] } & & & & 5-yr LR & & $\pm \mathrm{RT}$ & Subtype $^{\mathrm{b}}$ \\
\hline & $\geq 20 \mathrm{~mm}$ & 12 & 0 & & 0 & & Grade \\
\hline & $10-19 \mathrm{~mm}$ & 51 & 5 & & 9 & & \pm Neoadjuvant RT \\
\hline & $5-9 \mathrm{~mm}$ & 33 & 2 & & 5 & & \\
\hline
\end{tabular}


Table 4 (continued)

\begin{tabular}{|c|c|c|c|c|c|c|c|}
\hline Author & Classification & $N$ & LR & Metric & $\begin{array}{l}\text { LR rate } \\
(\%)\end{array}$ & $\begin{array}{l}\text { Adjuvant } \\
\text { therapy }\end{array}$ & $\begin{array}{l}\text { Cohort } \\
\text { heterogeneity }\end{array}$ \\
\hline & $1-4 \mathrm{~mm}$ & 61 & 3 & & 4 & & \\
\hline & $<1 \mathrm{~mm}$ & 59 & 10 & & 17 & & \\
\hline & Positive & 36 & 8 & & 22 & & \\
\hline \multirow[t]{7}{*}{ Jebsen [22] } & & & & 5-yr LR & & $\pm \mathrm{RT}(356)$ & Subtype ${ }^{b}$ \\
\hline & Wide + RT & NS & NS & & 7.0 & & Grade \\
\hline & Wide & NS & NS & & 20.0 & & \pm Neoadjuvant RT \\
\hline & Marginal+RT & NS & NS & & 18.0 & & \\
\hline & Marginal & NS & NS & & 43.0 & & \\
\hline & $\begin{array}{l}\text { Intralesional } \\
+\mathrm{RT}\end{array}$ & NS & NS & & 38.0 & & \\
\hline & Intralesional & NS & NS & & 74.0 & & \\
\hline \multirow[t]{7}{*}{ Liu [23] } & & & & 5-yr LR & & $\pm \mathrm{RT}$ & Subtype $^{b}$ \\
\hline & $\geq 30 \mathrm{~mm}$ & 9 & 0 & & 0.0 & & Grade \\
\hline & $20-29 \mathrm{~mm}$ & 21 & 2 & & 9.0 & & \\
\hline & $10-19 \mathrm{~mm}$ & 40 & 1 & & 3.0 & & \\
\hline & $5-9 \mathrm{~mm}$ & 23 & 10 & & 42.0 & & \\
\hline & $1-4 \mathrm{~mm}$ & 36 & 15 & & 42.0 & & \\
\hline & Positive & 52 & 37 & & 71.0 & & \\
\hline \multirow[t]{5}{*}{ Gronchi [8] } & & & & 5-yr LR & & $\pm \mathrm{RT}$ & Subtype \\
\hline & R0 & 874 & 87 & & 10.0 & & Grade \\
\hline & R1-close & 11 & 2 & & 20.0 & & \\
\hline & R1-positive & 106 & 29 & & 27.0 & & \\
\hline & $\mathrm{R} 2$ & 6 & 2 & & 33.0 & & \\
\hline \multirow[t]{4}{*}{ Novais [24] } & & & & 5-yr LR & & $\pm \mathrm{RT}$ & Subtype \\
\hline & $>20 \mathrm{~mm}$ & 35 & 0 & & 0.0 & & $\begin{array}{l} \pm \text { Neoadjuvant } \\
\text { therapy }\end{array}$ \\
\hline & $2.1-20 \mathrm{~mm}$ & 164 & 2 & & 2.0 & & \\
\hline & + or $\leq 2 \mathrm{~mm}$ & 49 & 5 & & 12.0 & & \\
\hline \multirow{3}{*}{$\begin{array}{l}\text { Maretty- } \\
\text { Nielsen [13] }\end{array}$} & & & & 5-yr LR & & $\pm \mathrm{RT}$ & Recurrent tumors \\
\hline & Wide & 636 & 76 & & 12 & & Subtype $^{\mathrm{b}}$ \\
\hline & IL/Marginal & 237 & 59 & & 25 & & Grade \\
\hline \multirow{4}{*}{$\begin{array}{l}\text { Willeumier } \\
{[14]}\end{array}$} & & & & Crude LR & & $\pm \mathrm{RT}$ & Subtype \\
\hline & $>2 \mathrm{~mm}$ & 38 & 3 & & 8.0 & & \\
\hline & $\leq 2 \mathrm{~mm}$ & 75 & 22 & & 30.0 & & \\
\hline & Positive & 12 & 6 & & 50.0 & & \\
\hline \multirow[t]{4}{*}{ Kainhofer [25] } & & & & 5-yr LR & & $\pm \mathrm{RT}$ & Prior excision \\
\hline & $\geq 1 \mathrm{~mm}$ & 83 & 10 & & 12 & & Subtype \\
\hline & $<1 \mathrm{~mm}$ & 16 & 6 & & 38 & & \\
\hline & Positive & 14 & 5 & & 37 & & \\
\hline \multirow[t]{7}{*}{ Harati [26] } & & & & 5-yr LR & & $\pm \mathrm{RT}$ & Subtype $^{b}$ \\
\hline & $>5 \mathrm{~mm}$, No RT & NS & NS & & 31.6 & & Grade \\
\hline & $\begin{array}{l}1-5 \\
\text { mm, No RT }\end{array}$ & NS & NS & & 32.2 & & \\
\hline & $\leq 1 \mathrm{~mm}$, No RT & NS & NS & & 31.4 & & \\
\hline & $>5 \mathrm{~mm}, \mathrm{RT}$ & NS & NS & & 28.4 & & \\
\hline & $1-5 \mathrm{~mm}, \mathrm{RT}$ & NS & NS & & 21.1 & & \\
\hline & $\leq 1 \mathrm{~mm}, \mathrm{RT}$ & NS & NS & & 29.1 & & \\
\hline
\end{tabular}


Table 4 (continued)

\begin{tabular}{|c|c|c|c|c|c|c|c|}
\hline Author & Classification & $N$ & LR & Metric & $\begin{array}{l}\text { LR rate } \\
(\%)\end{array}$ & $\begin{array}{l}\text { Adjuvant } \\
\text { therapy }\end{array}$ & $\begin{array}{l}\text { Cohort } \\
\text { heterogeneity }\end{array}$ \\
\hline & & & & 5-yr LR & & & \\
\hline & R0, No RT & 341 & 124 & & 36 & & \\
\hline & R1, No RT & 24 & 17 & & 71 & & \\
\hline & R0, RT & 249 & 71 & & 29 & & \\
\hline & $\mathrm{R} 1, \mathrm{RT}$ & 19 & 10 & & 54 & & \\
\hline \multirow[t]{5}{*}{ Gundle [27] } & & & & 5-yr LR & & $\pm \mathrm{RT}$ & Subtype \\
\hline & R0 & 1908 & 114 & & 6.0 & & Grade \\
\hline & $\mathrm{R} 1(+)$ & 278 & 47 & & 17.0 & & Prior excision \\
\hline & $\begin{array}{l}\mathrm{R} 1(+ \text { or }<1 \\
\mathrm{mm})\end{array}$ & 726 & 72 & & 10.0 & & \pm Neoadjuvant RT \\
\hline & $\mathrm{R} 2$ & 26 & 10 & & 38.0 & & \\
\hline
\end{tabular}

BRT brachytherapy, $I L$ intralesional, $L R$ local recurrence, $N S$ not stated, $R T$ radiotherapy, $R 0 / R 1 / R 2$ American Joint Committee on Cancer $\mathrm{R}$ classification

${ }^{a}$ High-grade sarcomas only

${ }^{\mathrm{b}}$ Including well-differentiated liposarcoma

is given. Other studies have reported similar results for tumors treated with adjuvant radiation therapy $[8,20,21,25,30,33,35]$. While other groups have presented data suggesting that surgical resection margins should be at least $10 \mathrm{~mm}$ in width to reduce the risk of local recurrence [11,23], surgical resection margins as close as 2 $\mathrm{mm}$ have been reported to be safe in other cohorts [14, 24]. But significant fractions of these patient populations were treated either with neoadjuvant therapy, post-operative radiation therapy, or both, confounding interpretation of the extent of margin width on local recurrence rates.

Additional anatomic and clinical factors may influence the adequacy of margin width as well, such as the tissue composition of the margin and the clinical setting of close or positive margins. Enneking discussed the potential role of anatomical barriers in reducing the risk of local recurrence in soft tissue sarcomas early on, a concept subsequently evaluated by the Scandinavian Sarcoma Group and Japanese Orthopaedic Association [3, 36, 37]. Although the type of tissue present at the resection margin did not appear to have a significant effect in this study, the numbers of cases available for study were too few to account for other important prognostic factors such as margin distance, tumor size, and adjuvant radiation therapy.

Gerrand and colleagues first assessed the impact of the type of positive surgical resection margin on recurrence (a planned close/positive margin adjacent to a critical anatomic structure, a positive margin incurred during reexcision of the tumor bed after a previous unplanned excision, or unplanned/unexpected positive margins) [38]. Subsequently known as the Toronto Margin Context Classification, this system has since been validated in follow-up studies $[16,27]$. This classification could not be assessed in this study because tumor bed re-excision specimens were excluded and the observed close/positive margins could not be correlated to those of clinical concern from available operative reports with certainty.

Other clinical and pathologic variables evaluated (histologic subtype of sarcoma, anatomic depth [superficial vs. deep soft tissue], distant metastasis, or lymphovascular invasion) did not significantly affect the risk of local recurrence in this case series, but this may be due to the limited numbers cases within these various subgroups. Although it is possible that these factors may affect the potential for local recurrence, their effects, if any, appear minor in comparison to other more important factors such as surgical resection margin status, administration of adjuvant radiation therapy, and tumor size.

Another goal of this study was to determine what margin classification system should be used in reporting the status of surgical resection margins. Direct comparisons of the American Joint Committee on Cancer R system, Musculoskeletal Tumor Society classification, and margin distance methods have not been previously reported. Both the Musculoskeletal Tumor Society system and margin distance reporting classifications showed increased accuracy for predicting local recurrence within $2 \frac{1}{2}$ years of surgical resection than the American Joint Committee on Cancer $\mathrm{R}$ system, even after adjusting for critical confounding factors. In addition, both the Musculoskeletal Tumor Society system and margin distance reporting classifications showed overall better diagnostic performance in predicting local recurrence within $2 \frac{1}{2}$ years of surgical resection than the American Joint Committee on Cancer R system when dichotomized at optimal cutoff values. The negative predictive value of an R0 margin in the American Joint Committee on Cancer R 
system is clearly inferior to more conservative margin reporting systems that consider negative but close margins (i.e., marginal margins or tumor clearance $\leq 1 \mathrm{~mm}$ with radiation therapy or $\leq 5 \mathrm{~mm}$ without radiation therapy) as indicative of an increased risk of local recurrence. Therefore, at our institution, we now report both the Musculoskeletal Tumor Society margin classification as well as the metric distance and tissue composition of the closest resection margin, since we believe that the American Joint Committee on Cancer system is less informative in predicting the risk of local recurrence.

Finally, preliminary evidence is provided here to define the minimum number of tissue sections necessary to adequately evaluate the status of surgical resection margins by histopathologic examination. Philosophical arguments aside, the practice of "proving a negative" or failing to reject the null hypothesis, $H_{0}$ : "the resection margins are negative" is basically a statistical sampling problem. Theoretically (and ignoring the possibility of false positives, such as when excess ink is identified on tumor either incised by the prosector or when the tumor capsule inadvertently slips during prosection), only one section would be adequate if it unequivocally documents the presence of a positive margin. But how many sections should be submitted before we accept (or fail to reject) this null hypothesis? The probability of a false negative conclusion that the margins are negative when they are in fact positive is directly related to the sample size, which in this situation is the number of sections taken to evaluate the surgical resection margins. Submitting too few sections reduces statistical power, whereas submitting too many is laborious and not cost-effective practice with respect to the "law of diminishing returns". Although the analysis presented here is not an optimal, statistically rigorous power analysis, submission of six or more perpendicular sections was associated with significant increases in the hazard and odds ratios for local recurrence in the presence of a positive or close surgical resection margin.

Pathologists intuitively apply the principles of Bayesian probability in assessing surgical resection margins (as exemplified in Supplementary Fig. 1) by submitting more sections from margins that are close or concerning on gross examination. However, careful gross inspection of surgical resection margins can be misleading. The outlier case described herein that recurred locally despite grossly wide resection margins of at least $4 \mathrm{~mm}$ of skeletal muscle (and that was subsequently sampled inadequately) is illustrative of this point. Therefore, microscopic examination of six to eight perpendicular sections in total from all margins $<2 \mathrm{~cm}$ in width appears to be a practical compromise and a reasonable recommendation.

In summary, Musculoskeletal Tumor Society wide/radical margins or margin widths of $5 \mathrm{~mm}$ (without adjuvant radiation therapy) or $1 \mathrm{~mm}$ (with adjuvant radiation therapy) appear to define the minimum safe surgical resection margins necessary to decrease the likelihood of local recurrence of high-grade pleomorphic soft tissue sarcomas of the extremity or trunk. Using these definitions, the Musculoskeletal Tumor Society and margin distance classifications are more predictive of clinical outcomes than the American Joint Committee on Cancer R system, which suffers from low sensitivity and negative predictive value. Surgical resection margins for soft tissue sarcoma should be carefully examined at the time of gross inspection, with a total of six or more sections submitted from margins $<2 \mathrm{~cm}$ from tumor.

\section{Compliance with ethical standards}

Conflict of interest The authors declare that they have no conflict of interest.

Publisher's note: Springer Nature remains neutral with regard to jurisdictional claims in published maps and institutional affiliations.

\section{References}

1. Casali PG, Abecassis N, Bauer S, Biagini R, Bielack S, Bonvalot $S$, et al. Soft tissue and visceral sarcomas: ESMO-EURACAN Clinical Practice Guidelines for diagnosis, treatment and followup. Ann Oncol. 2018;29:iv51-iv67.

2. von Mehren M, Randall RL, Benjamin RS, Boles S, Bui MM, Ganjoo KN, et al. Soft tissue sarcoma, version 2.2018, NCCN Clinical Practice Guidelines in Oncology. J Natl Compr Canc Netw. 2018;16:536-63.

3. Enneking WF, Spanier SS, Goodman MA. A system for the surgical staging of musculoskeletal sarcoma. 1980. Clin Orthop Relat Res. 2003;415:4-18.

4. Laurini JA, Cooper K, Fletcher CDM, Folpe AL, Gannon FH, Hunt JL, et al. Protocol for the examination of specimens from patients with soft tissue tumors. [CAP Web site]; 2017. www.cap. org/cancerprotocols. Accessed 24 October 2018.

5. Gress DM, Edge SB, Greene FL, Washington MK, Asare EA, Brierley JD, et al. Principles of cancer staging. In: Amin MB, Edge SB, Greene FL, Byrd DR, Brookland RK, Washington MK, editors. AJCC Cancer Staging Manual. 8th ed. Switzterland: Springer International Publishing; 2017.

6. Kandel R, Coakley N, Werier J, Engel J, Ghert M, Verma S. Sarcoma disease site group of cancer care ontario's program in evidence-based care. Surgical margins and handling of soft-tissue sarcoma in extremities: a clinical practice guideline. Curr Oncol. 2013;20:e247-54

7. Trovik CS, Gustafson P, Bauer HCF, Saeter G, Klepp R, Berlin O, et al. Consequences of local recurrence of soft tissue sarcoma: 205 patients from the Scandinavian Sarcoma Group Register. Acta Orthop Scand. 2000;71:488-95.

8. Gronchi A, Lo Vullo S, Colombo C, Collini P, Stacchiotti S, Mariani L, et al. Extremity soft tissue sarcoma in a series of patients treated at a single institution: local control directly impacts survival. Ann Surg. 2010;251:506-11.

9. McCormick D, Mentzel T, Beham A, Fletcher CD. Dedifferentiated liposarcoma: clinicopathologic analysis of 32 cases suggesting a better prognostic subgroup among pleomorphic sarcomas. Am J Surg Pathol. 1994;18:1213-23. 
10. Pisters PWT. Clinical evaluation and treatment of soft tissue tumors. In: Goldblum J, Folpe A, Weiss S, editors. Enzinger and Weiss's Soft Tissue Tumors. 6th ed. Philadelphia, PA: Elsevier Inc; 2014.

11. McKee MD, Liu DF, Brooks JJ, Gibbs JF, Driscoll DL, Kraybill WG. The prognostic significance of margin width for extremity and trunk sarcoma. J Surg Oncol. 2004;85:68-76.

12. Kim YB, Shin KH, Seong J, Roh JK, Kim GE, Hahn SB, et al. Clinical significance of margin status in postoperative radiotherapy for extremity and truncal soft-tissue sarcoma. Int J Radiat Oncol Biol Phys. 2008;70:139-44.

13. Maretty-Nielsen K, Aggerholm-Pedersen N, Safwat A, Jørgensen $\mathrm{PH}$, Hansen BH, Baerentzen S, et al. Prognostic factors for local recurrence and mortality in adult soft tissue sarcoma of the extremities and trunk wall: a cohort study of 922 consecutive patients. Acta Orthop. 2014;85:323-32.

14. Willeumier J, Fiocco M, Nout R, Dijkstra S, Aston W, Pollock R, et al. High-grade soft tissue sarcomas of the extremities: surgical margins influence only local recurrence not overall survival. Int Orthop. 2015;39:935-41.

15. van Praag VM, Rueten-Budde AJ, Jeys LM, Laitinen MK, Pollock $\mathrm{R}$, Aston $\mathrm{W}$, et al. A prediction model for treatment decisions in high-grade extremity soft-tissue sarcomas: personalised sarcoma care (PERSARC). Eur J Cancer. 2017;83:313-23.

16. O'Donnell PW, Griffin AM, Eward WC, Sternheim A, Catton $\mathrm{CN}$, Chung PW, et al. The effect of the setting of a positive surgical margin in soft tissue sarcoma. Cancer. 2014;120: 2866-75.

17. Willeumier JJ, Rueten-Budde AJ, Jeys LM, Laitinen M, Pollock $\mathrm{R}$, Aston $\mathrm{W}$, et al. Individualised risk assessment for local recurrence and distant metastases in a retrospective transatlantic cohort of 687 patients with high-grade soft tissue sarcomas of the extremities: a multistate model. BMJ Open. 2017;7:e012930.

18. Fiore M, Ford S, Callegaro D, Sangalli C, Colombo C, Radaelli S, et al. Adequate local control in high-risk soft tissue sarcoma of the extremity treated with surgery alone at a reference centre: should radiotherapy still be a standard? Ann Surg Oncol. 2018;25: 1536-43.

19. Trovik CS, Bauer HCF, Berlin Ö, Tukiainen E, Erlanson M, Gustafson P, et al. Local recurrence of deep-seated, high-grade, soft tissue sarcoma: 459 patients from the Scandinavian Sarcoma Group Register. Acta Orthop Scand. 2001;72:160-6.

20. Gronchi A, Casali PG, Mariani L, Miceli R, Fiore M, Lo Vullo S, et al. Status of surgical margins and prognosis in adult soft tissue sarcomas of the extremities: a series of patients treated at a single institution. J Clin Oncol. 2005;23:96-104.

21. Dickinson IC, Whitwell DJ, Battistuta D, Thompson B, Strobel N, Duggal A, et al. Surgical margin and its influence on survival in soft tissue sarcoma. Anz J Surg. 2006;76:104-9.

22. Jebsen NL, Trovik CS, Bauer HCF, Rydholm A, Monge OR, Hall $\mathrm{KS}$, et al. Radiotherapy to improve local control regardless of surgical margin and malignancy grade in extremity and trunk wall soft tissue sarcoma: a Scandinavian Sarcoma Group study. Int J Radiat Oncol Biol Phys. 2008;71:1196-203.

23. Liu CY, Yen CC, Chen WM, Chen TH, Chen PC, Wu HT, et al. Soft tissue sarcoma of extremities: the prognostic significance of adequate surgical margins in primary operation and reoperation after recurrence. Ann Surg Oncol. 2010;17:2102-11.

24. Novais EN, Demiralp B, Alderete J, Larson MC, Rose PS, Sim FH. Do surgical margin and local recurrence influence survival in soft tissue sarcomas? Clin Orthop Relat Res. 2010;468:3003-11.

25. Kainhofer V, Smolle MA, Szkandera J, Liegl-Atzwanger B, Maurer-Ertl W, Gerger A, et al. The width of resection margins influences local recurrence in soft tissue sarcoma patients. Eur J Surg Oncol. 2016;42:899-906.

26. Harati K, Goertz O, Pieper A, Daigeler A, Joneidi-Jafari H, Niggemann $\mathrm{H}$, et al. Soft tissue sarcomas of the extremities: surgical margins can be close as long as the resected tumor has no ink on it. Oncologist. 2017;22:1400-10.

27. Gundle KR, Kafchinski L, Gupta S, Griffin AM, Dickson BC, Chung PW, et al. Analysis of margin classification systems for assessing the risk of local recurrence after soft tissue sarcoma resection. J Clin Oncol. 2018;36:704-9.

28. Enneking WF, Spanier SS, Malawer MM. The effect of the anatomic setting on the results of surgical procedures for soft parts sarcoma of the thigh. Cancer. 1981;47:1005-22.

29. Alho A, Alvegård TA, Berlin Ö, Ranstam J, Rydholm A, Rööser B, et al. Surgical margin in soft tissue sarcoma: the Scandinavian Sarcoma Group experience. Acta Orthop Scand. 1989;60:687-92.

30. Bell RS, O'Sullivan B, Liu FF, Powell J, Langer F, Fornasier VL, et al. The surgical margin in soft-tissue sarcoma. J Bone Joint Surg Am. 1989;71:370-5.

31. Stotter AT, A'Hern RP, Fisher C, Mott AF, Fallowfield ME, Westbury G. The influence of local recurrence of extremity soft tissue sarcoma on metastasis and survival. Cancer. 1990;65: 1119-29.

32. Herbert SH, Corn BW, Solin LJ, Lanciano RM, Schultz DJ, McKenna WG, et al. Limb-preserving treatment for soft tissue sarcomas of the extremities: the significance of surgical margins. Cancer. 1993;72:1230-8.

33. Pisters PWT, Leung DHY, Woodruff J, Shi W, Brennan MF. Analysis of prognostic factors in 1,041 patients with localized soft tissue sarcomas of the extremities. J Clin Oncol. 1996;14:1679-89.

34. Cates JMM. Modeling continuous prognostic factors in survival analysis: implications for tumor staging and assessing chemotherapy effect in osteosarcoma. Am J Surg Pathol. 2018;42:485-91.

35. Pisters PWT, Pollock RE, Lewis VO, Yasko AW, Cormier JN, Respondek PM, et al. Long-term results of prospective trial of surgery alone with selective use of radiation for patients with $\mathrm{T} 1$ extremity and trunk soft tissue sarcomas. Ann Surg. 2007;246:675-81.

36. Kawaguchi N, Matumoto S, Manabe J. New method of evaluating the surgical margin and safety margin for musculoskeletal sarcoma, analysed on the basis of 457 surgical cases. J Cancer Res Clin Oncol. 1995;121:555-63.

37. Rydholm A, Rööser B. Surgical margins for soft-tissue sarcoma. J Bone Joint Surg Am. 1987;69:1074-8.

38. Gerrand CH, Wunder JS, Kandel RA, O'Sullivan B, Catton CN, Bell RS, et al. Classification of positive margins after resection of soft-tissue sarcoma of the limb predicts the risk of local recurrence. J Bone Joint Surg Br. 2001;83B:1149-55. 